\title{
Antarctic Temperature at Orbital Timescales Controlled by Local Summer Duration
}

\section{Citation}

Huybers, Peter J., and George Denton. 2008. Antarctic temperature at orbital timescales controlled by local summer duration. Nature Geoscience 1: 787-792.

\section{Published Version}

http://dx.doi.org/10.1038/ngeo311

\section{Permanent link}

http://nrs.harvard.edu/urn-3:HUL.InstRepos:3355830

\section{Terms of Use}

This article was downloaded from Harvard University's DASH repository, and is made available under the terms and conditions applicable to Other Posted Material, as set forth at http:// nrs.harvard.edu/urn-3:HUL.InstRepos:dash.current.terms-of-use\#LAA

\section{Share Your Story}

The Harvard community has made this article openly available.

Please share how this access benefits you. Submit a story.

Accessibility 


\title{
Antarctic temperature at orbital timescales controlled by local summer duration
}

\author{
PETER HUYBERS ${ }^{1 *}$ AND GEORGE DENTON² \\ ${ }^{1}$ Harvard University, Cambridge, Massachusetts 02138, USA \\ ${ }^{2}$ University of Maine, Orono, Maine 04469, USA \\ *e-mail: phuybers@fas.harvard.edu
}

Published online: 21 September 2008; doi:10.1038/nge0311

During the late Pleistocene epoch, proxies for Southern Hemisphere climate from the Antarctic ice cores vary nearly in phase with Northern Hemisphere insolation intensity at the precession and obliquity timescales. This coherence has led to the suggestion that Northern Hemisphere insolation controls Antarctic climate. However, it is unclear what physical mechanisms would tie southern climate to northern insolation. Here we call on radiative equilibrium estimates to show that Antarctic climate could instead respond to changes in the duration of local summer. Simple radiative equilibrium dictates that warmer annual average atmospheric temperatures occur as a result of a longer summer, as opposed to a more intense one, because temperature is more sensitive to insolation when the atmosphere is cooler. Furthermore, we show that a single-column atmospheric model reproduces this radiative equilibrium effect when forced exclusively by local Antarctic insolation, generating temperature variations that are coherent and in phase with proxies of Antarctic atmospheric temperature and surface conditions. We conclude that the duration of Southern Hemisphere summer is more likely to control Antarctic climate than the intensity of Northern Hemisphere summer with which it (often misleadingly) covaries. In our view, near interhemispheric climate symmetry at the obliquity and precession timescales arises from a northern response to local summer intensity and a southern response to local summer duration.

Southern Hemisphere climate proxies follow northern summer insolation intensity ${ }^{1-7}$, leading to the common interpretation that northern insolation controls southern climate, at least at the obliquity and precession timescales ${ }^{2,5,7}$. Proposed mechanisms include northern insolation influencing atmospheric $\mathrm{CO}_{2}$ (refs 8,9), North Atlantic Deep Water affecting the Southern Ocean ${ }^{10,11}$, and variations in the extent of northern glaciation influencing the south ${ }^{7}$. However, such explanations are problematic because conventional statistical techniques indicate that southern changes are in phase with or lead those in the north ${ }^{1,2,4,8,12-15}$ - a situation Mercer ${ }^{12}$ called 'a fly in the ointment of the Milankovitch theory'.

Although northern forcing of Antarctic climate cannot be ruled out, particularly if small or otherwise difficult-to-detect northern perturbations precede those in the south ${ }^{8}$, the lack of an obvious, operative mechanism to produce symmetric interhemispheric changes at the precession period prompts further examination of the connection between Earth's orbit and southern climate. Our focus is on the obliquity and precession bands in the climate record, largely to the exclusion of more rapid variations and of $\sim 100 \mathrm{kyr}$ glacial cycles. Nonetheless, the climate spectrum is coupled across timescales ${ }^{16}$, and we expect investigation of the orbital response to improve our understanding of the continuum of climate variability.

\section{RADIATIVE EQUILIBRIUM AND THE DURATION OF SUMMER}

We build on the fact that the duration of southern summer covaries almost identically with northern summer insolation intensity (Fig. 1). (Here summer duration is defined as the number of days in which the diurnal average insolation intensity exceeds $250 \mathrm{~W} \mathrm{~m}^{-2}$, a threshold which gives good agreement with northern solstice intensity values.) This covariation arises because the precession of the equinoxes results in opposite effects on the intensity and duration of summer seasons within a single hemisphere $\mathrm{e}^{17}$, and opposite effects on intensity and duration of summer seasons between the two hemispheres. Increases in obliquity cause symmetric increases in intensity and duration of summer at high latitudes in both hemispheres. Therefore, although the signature of orbital variations is discernible within high-latitude southern climate records, signal processing alone cannot distinguish between northern or southern insolation forcing. Determining the origins of orbital-period variability in southern climate proxies requires identification of physical mechanisms that connect insolation at the top of the atmosphere with proxy signals in ice and in marine sediments.

Perhaps the most fundamental relationship between temperature and insolation is that of radiative equilibrium, $F=\sigma T^{4} . F$ is the absorbed incoming solar radiation, $T$ is the temperature in Kelvin and $\sigma$ is the Stefan-Boltzmann constant. The precession of the equinoxes redistributes insolation throughout the seasons but has no influence on the total annual insolation $^{18}$. Therefore, there must be a nonlinear response to insolation if precession is to exert any control on mean annual temperature. Radiative equilibrium furnishes such a nonlinearity. The radiative equilibrium temperature is less sensitive to insolation at higher temperatures, $\mathrm{d} T / \mathrm{d} F=1 /\left(4 \sigma T^{3}\right)$, with a value of $0.41 \mathrm{~K} /\left(\mathrm{W} \mathrm{m}^{-2}\right)$ for typical winter atmospheric temperatures in Antarctica $(T=220 \mathrm{~K})$ and $0.25 \mathrm{~K} /\left(\mathrm{W} \mathrm{m}^{-2}\right)$ for summer conditions $(T=260 \mathrm{~K})$. Thus, the annual average radiative equilibrium temperature will be greatest when insolation is spread away from peak summer intensity-as occurs when precession 


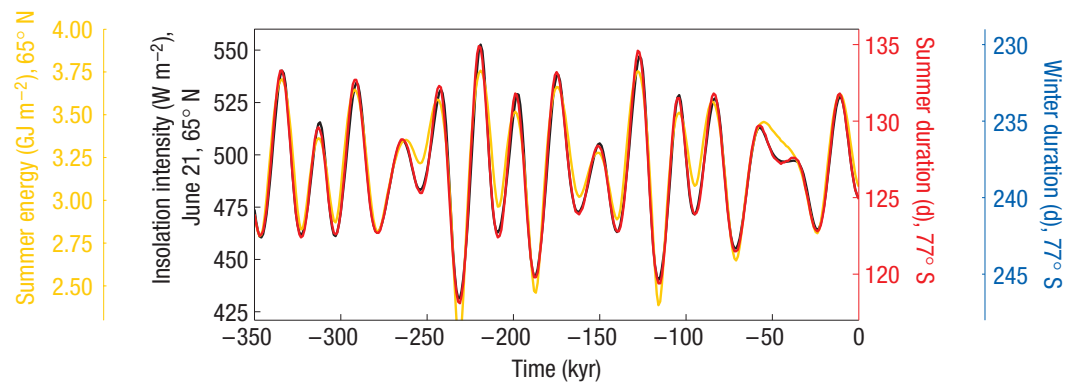

Figure 1 Different measures of insolation covary with one another. Examples are the summer energy ${ }^{17}$ at $65^{\circ} \mathrm{N}$ using a threshold of $400 \mathrm{~W} \mathrm{~m}{ }^{-2}$ (yellow), the diurnal average insolation intensity at the top of the atmosphere for the summer solstice at $65^{\circ} \mathrm{N}$ (black), the duration of the summer at $77^{\circ} \mathrm{S}$ (red, measured as the number of days whose diurnal average insolation exceeds $250 \mathrm{~W} \mathrm{~m}^{-2}$ ) and the number of winter days (hidden beneath the summer duration curve, measured as days below $250 \mathrm{~W} \mathrm{~m}^{-2}$; note the reversed $y$ axis).

aligns aphelion with summer solstice. We note that Milankovitch ${ }^{19}$ also considered the influence of orbital variations on the radiative equilibrium temperature but used a fixed half-year interval, thereby excluding effects associated with changes in the duration of the seasons. Rubincam ${ }^{20}$ determined that annual average radiative equilibrium temperature would be highest for an orbit that aligns aphelion with summer solstice but considered only cases with neither heat capacity nor an atmosphere.

The influence of orbital variations on radiative equilibrium temperature can be more fully demonstrated using a simple energy balance model (see Methods section). The seasonal cycle of insolation at $77^{\circ} \mathrm{S}$, the latitude of the Dome $\mathrm{F}$ ice core on the high plateau of the East Antarctic Ice Sheet, is considered under two scenarios: one when Earth is at perihelion during southern summer solstice, averaged over the 15 occurrences in the past $350 \mathrm{kyr}$, and another averaged over the times when aphelion coincides with summer solstice (Fig. 2). Although the total insolation is equivalent in the two cases of precessional alignment, the second forcing scenario leads to warmer annual average temperatures because increased insolation in spring or early summer (when atmospheric temperatures are lower) causes more warming relative to the magnitude of cooling caused by decreased insolation during mid-to-late summer (when temperatures are higher). Some studies call on related changes in autumn ${ }^{18}$ or spring $^{21,22}$ insolation intensity to influence climate. Here we attempt to address the full seasonal distribution of insolation, but note that spring insolation intensity at high southern latitudes varies closely with the duration of the summer (assuming the calendar is referenced to northern spring equinox).

Is simple radiative balance a reasonable first-order description of the atmospheric temperature variability? To explore this question in more detail, we examine the response of the Single Column Atmospheric Model (SCAM, see Methods section) ${ }^{23,24}$ to variations in insolation. When run over the course of the past 350,000 years at Dome F, SCAM produces a mean annual tropospheric temperature that corresponds to the changes in duration of the Antarctic summer. Subtracting the seasonal cycle of temperature associated with perihelion occurring at summer solstice from that associated with aphelion at summer solstice reveals a pattern of anomalous spring and early summer warming that extends from the lower troposphere $\left(\sim 5^{\circ} \mathrm{C}\right)$ up through the stratosphere $\left(\sim 10^{\circ} \mathrm{C}\right.$, Fig. 2$)$. An increase in obliquity also raises the atmospheric temperature in SCAM, as well as in the simple energy-balance model, but here we focus on precession because the obliquity-induced changes are symmetric between the hemispheres and, thus, do not enable us to distinguish between southern ${ }^{3,6}$ or northern ${ }^{2,7,8}$ control. Note that the peculiarities of the Antarctic climate represented in SCAM seem to make local radiative balance an important control on temperature. A strong thermal inversion layer exists over Antarctica for most of the year ${ }^{25}$ because the ice surface emits radiation more efficiently than the atmosphere. As a result, convection and the exchange of heat between the troposphere and the ice surface is inhibited. Furthermore, Antarctic temperatures rarely exceed the freezing point, and such low temperatures are associated with consistently small amounts of water vapour in the atmosphere, hence muting changes in emissivity and absorptivity.

\section{COMPARISON OF MODEL RESULTS AGAINST ICE-CORE PROXIES}

The SCAM results are compared against the Dome F (ref. 7) ice-core record of $\delta^{18} \mathrm{O}_{\text {ice }}$ (Fig. 3). A full interpretation of this proxy requires an understanding of the tracer's time-variable evaporation, transport, precipitation, and ultimate densification into ice ${ }^{26,27}$, but we adopt the simple and common interpretation of mean annual atmospheric temperature above the deposition site. The variability in SCAM's annual average atmospheric temperature is coherent and consistent with an in-phase relationship with the Dome F $\delta^{18} \mathrm{O}_{\text {ice }}$ record at both the obliquity and the precession bands (see Fig. 4). SCAM's temperature results are likewise coherent and in phase with the temperature proxy record from Dome $\mathrm{C}$, which is also located on the high East Antarctic plateau (see Supplementary Information). Similar orbital-band variability is generated when SCAM is specified to have zero heat-flux convergence, double or half the modern $\mathrm{CO}_{2}$ concentration, or is run in a clear-sky mode-indicating that the orbital response is robust to changes in the model parametrization and to changes in climate. These model results support our hypothesis that local variations in the duration of summer control the orbital-period variability in Antarctic atmospheric temperature. In this view, similarities between southern proxies and northern summer insolation intensity are a red herring, pointing to the wrong hemisphere.

$\delta \mathrm{O}_{2} / \mathrm{N}_{2}$ ice-core records from Dome $\mathrm{F}$ (ref. 7) and another site on the high East Antarctic Plateau at Vostok $^{28}$ affords an additional constraint regarding the influence of orbital variations on Antarctica's climate. $\delta \mathrm{O}_{2} / \mathrm{N}_{2}$ seems to follow the intensity of local summer insolation, possibly because maximum seasonal temperatures at the surface alter ice crystals and gas close-off depths, although the exact mechanism remains uncertain ${ }^{28}$. The maximum seasonal surface temperatures obtained in SCAM follow summer solstice insolation and are coherent and in phase with the $\delta \mathrm{O}_{2} / \mathrm{N}_{2}$ signal at both the obliquity and the precession periods (Fig. 3 and Supplementary Information). Therefore, SCAM 


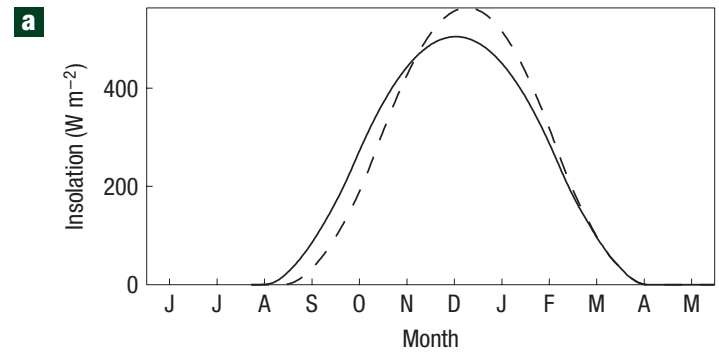

G

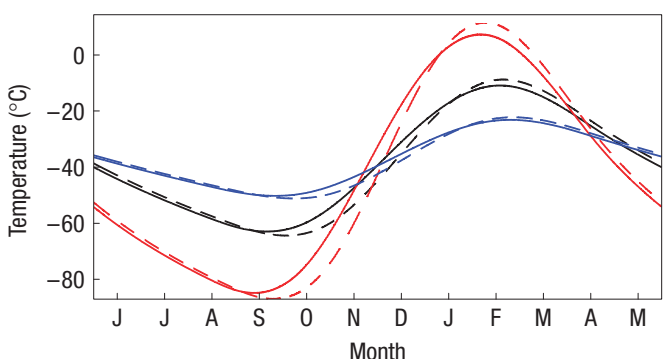

e

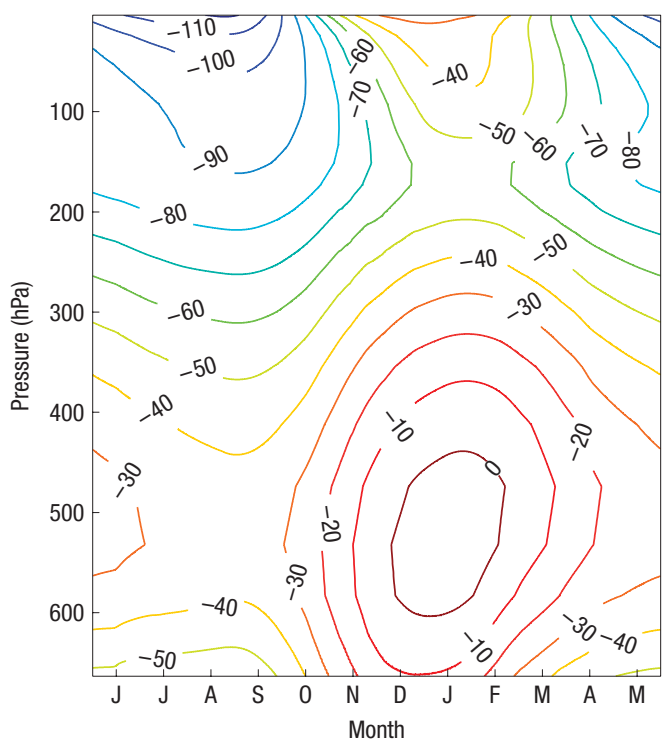

b

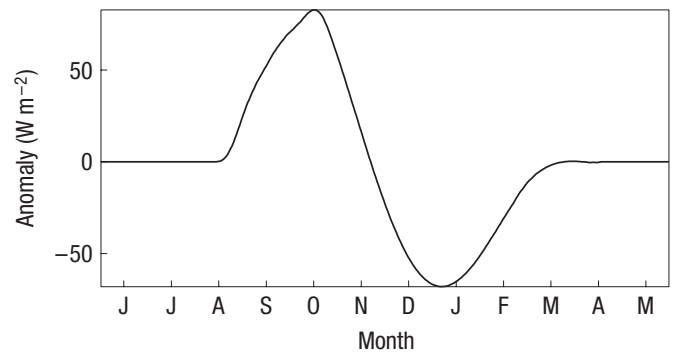

d

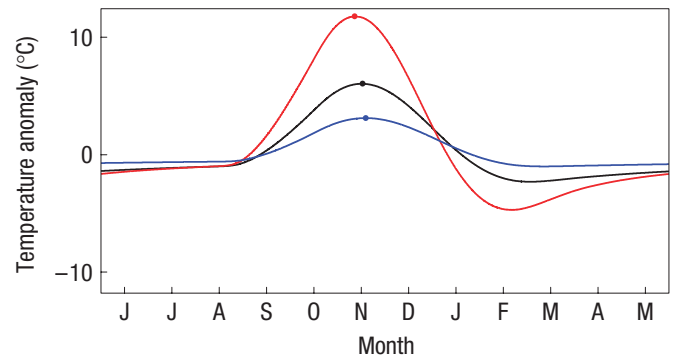

f

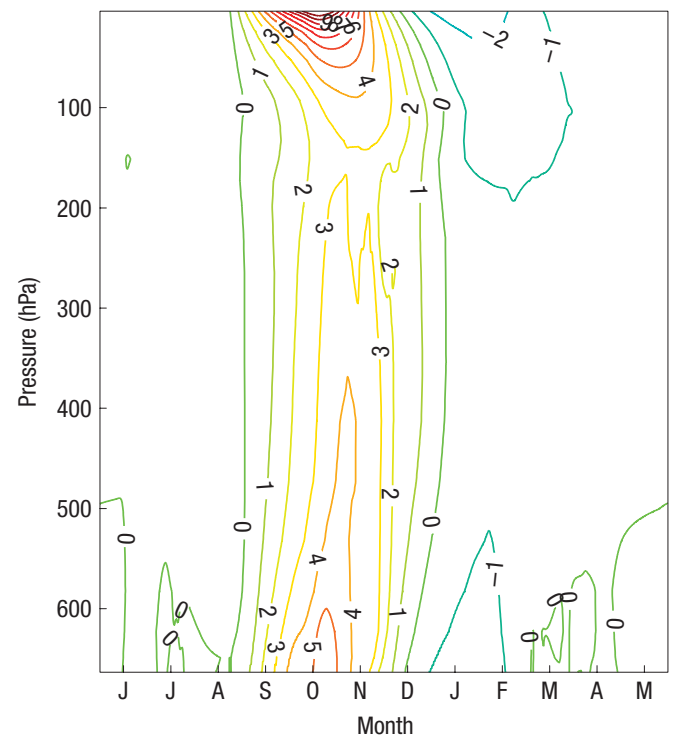

Figure 2 The seasonal cycle in Antarctic insolation and atmospheric temperature. a, The diurnal average insolation in SCAM averaged over runs in which aphelion (solid) and perihelion (dashed) coincide with southern summer solstice; $\mathbf{b}$, the difference, which averages to zero. c, Runs of the energy-balance model forced with summer aphelion insolation (solid) and summer perihelion insolation (dashed); $\mathbf{d}$, their differences, which show more warming than cooling for summer aphelion. Runs in $\mathbf{c}$ and $\mathbf{d}$ have a heat capacity of $2,500 \mathrm{~kJ}^{\circ} \mathrm{C}^{-1}$ (black) and half (blue) and twice (red) this value. e, Contour plot of the average seasonal cycle in temperature $\left({ }^{\circ} \mathrm{C}\right.$ ) in SCAM averaged over years when perihelion coincides with summer solstice; $\mathbf{f}$, the relative amount of warming for average conditions when aphelion coincides with summer solstice. Time is plotted from 1 June to 31 May.

responds to insolation at Dome $\mathrm{F}$ in a manner consistent with the $\delta \mathrm{O}_{2} / \mathrm{N}_{2}$ proxy for surface conditions and the $\delta^{18} \mathrm{O}_{\text {ice }}$ proxy for mean annual atmospheric temperature - in particular, reproducing their antiphased precession variability.

There do exist two important discrepancies between the atmospheric temperatures derived from SCAM and the orbitalperiod variations in temperature estimated from the Dome $\mathrm{F}$ ice core. First, according to the age model of ref. 7, Dome F temperatures slightly lag northern summer solstice insolation in the obliquity (by $46^{\circ} \pm 63^{\circ}, 2 \sigma$ uncertainty) and precession (by $18^{\circ} \pm 38^{\circ}$ ) bands, whereas SCAM predicts that insolation and temperature are in phase. Phase uncertainties arise both because of uncertainty in the ice-core chronology and because of imperfect coherence between northern summer insolation intensity and temperature, and render the observations consistent with SCAM's prediction of an in-phase relationship (see Supplementary Information), particularly given additional sources of uncertainty related to seasonality in the deposition of snow $^{29}$ and the physical relationship between $\delta \mathrm{O}_{2} / \mathrm{N}_{2}$ and insolation ${ }^{28}$. Alternatively, the phase lag of temperature with respect to insolation could be real, possibly resulting from slow feedbacks within the climate system that involve processes such as atmospheric $\mathrm{CO}_{2}$.

Second, the average peak-to-trough amplitude of the temperature change in SCAM is just over $1^{\circ} \mathrm{C}$, whereas reconstructed temperatures from ice-core proxies ${ }^{6,7}$ have an amplitude of about $3{ }^{\circ} \mathrm{C}$ at the orbital bands. The proxy reconstruction may exaggerate the variability in annual mean temperature because of seasonality in the deposition of snow or 


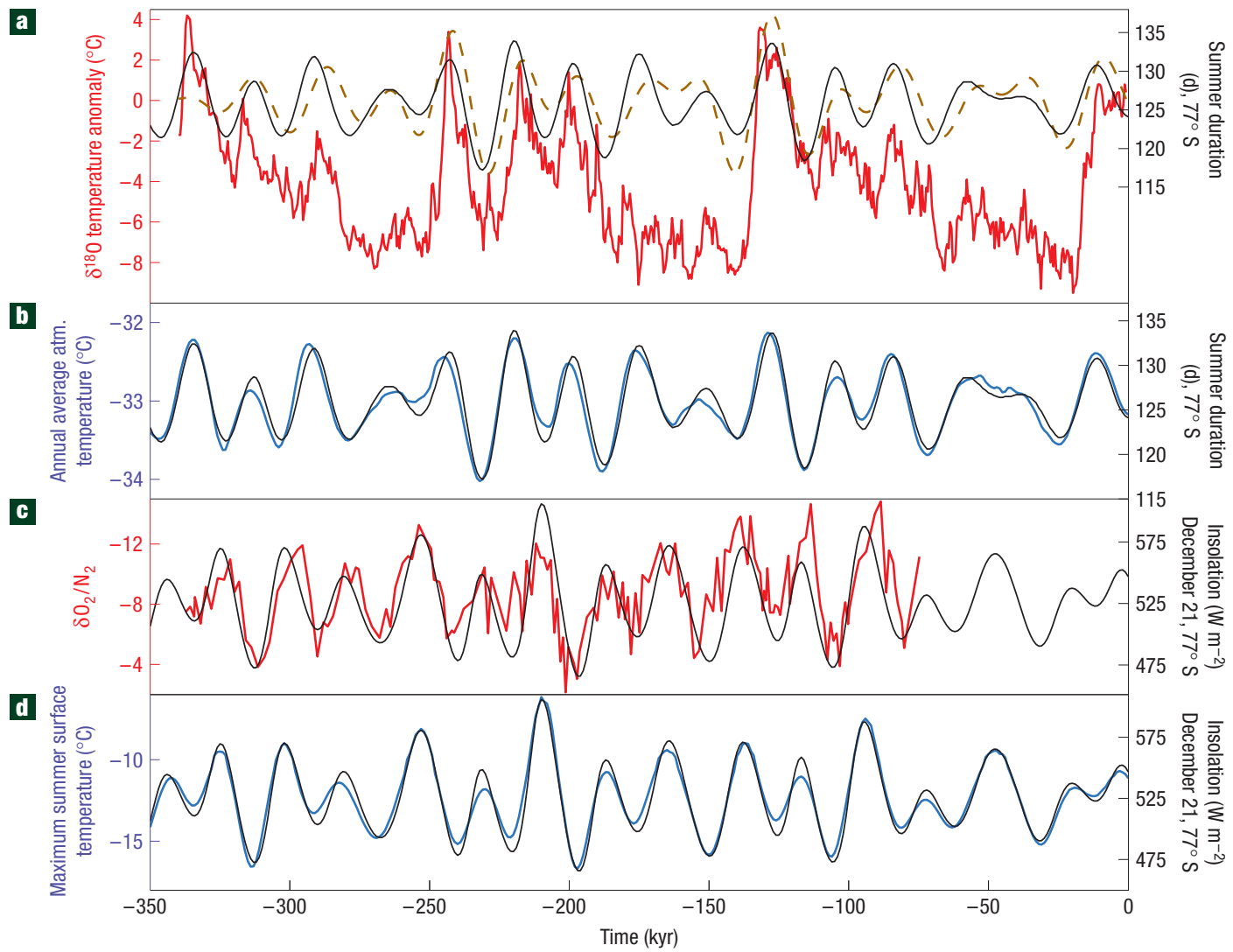

Figure 3 Temperature variability in the Antarctic over the past 350 kyr. a, The atmospheric temperature anomaly estimated from Dome $F$ (ref. 7) (red), the orbital period temperature variability (dashed brown, band-pass filtered between $1 / 45 \mathrm{kyr}$ and $1 / 17 \mathrm{kyr}$ ) and the southern summer duration (black). b. The annual average tropospheric temperature from SCAM (blue) and the southern summer duration (black). c, The Dome $\mathrm{F} \delta \mathrm{O}_{2} / \mathrm{N}_{2}$ record (red) and the southern summer solstice insolation intensity (black). d, The maximum summer surface temperature in SCAM (blue, daily average) and the southern solstice insolation intensity (black).

because of changes in the relationship between temperature and $\delta^{18} \mathrm{O}_{\text {ice }}$ (ref. 27), but a more likely explanation involves climate feedbacks. Antarctic sea ice seems to covary with changes in atmospheric temperature ${ }^{30}$. The complement of a long summer is a short winter, and we suggest that a short winter may decrease the production and extent of Antarctica's apron of sea ice. (A related suggestion is for spring insolation intensity, which covaries with summer duration, to influence Antarctic sea ice ${ }^{22}$.) Furthermore, atmospheric $\mathrm{CO}_{2}$ has also covaried with Antarctic temperature over the past 800,000 years ${ }^{4,31,32} \cdot \mathrm{CO}_{2}$ variation may itself be linked with changes in Antarctic sea ice ${ }^{33,34}$, and would tend to cause symmetric changes between the poles because it is well mixed in the atmosphere ${ }^{9}$. Thus we speculate that the increasing summer and decreasing winter durations caused by the alignment of aphelion with southern summer solstice coordinates the effects of summer radiation balance, winter sea ice and atmospheric $\mathrm{CO}_{2}$ so as to increase Antarctic temperature. Variations in sea ice and $\mathrm{CO}_{2}$ may also explain why climate variations similar to those in Antarctica are observed in mid-latitude southern marine and continental environments ${ }^{9}$.

\section{IMPLICATIONS FOR NORTHERN AND SOUTHERN CLIMATE}

Local control of Antarctic temperature conceptually frees southern climate from northern forcing at the precession and obliquity timescales. It enables an alternative hypothesis in which the near symmetry of interhemispheric changes during the late Pleistocene depends on northern climate responding primarily to summer intensity (Milankovitch's hypothesis ${ }^{2,19,35,36}$ ) and southern climate responding primarily to the duration of summer and winter seasons (a version of Adhémar's hypothesis ${ }^{37}$ ). These contrasting northern and southern responses may reflect the contrasting distributions of land and ocean-and hence ice sheets-in the two hemispheres. The large northern ice sheets maintained extensive melting margins on land, reached equatorward as far south as $37^{\circ} \mathrm{N}$ in central North America and lost much of their ice through surface melting atop land. Increased melting along a land margin will tend to decrease the area and volume of such ice sheets and thereby increase atmospheric temperatures through albedo and elevation effects. Thus, insomuch as the alignment of perihelion with northern summer serves to increase ablation, it will also tend to increase northern temperature. In contrast, the polar-centric Antarctic Ice Sheet covers nearly the entire continent, even in today's interglacial climate. Most of its ice loss is pinned at the periphery of the continent, occurring through calving and basal melting of ice shelves. As a consequence, the area and volume of the Antarctic ice sheet is relatively stable ${ }^{38}$, affording little leverage for the albedo and elevation feedbacks to move atmospheric temperature. We suggest that the relative lack of ice-temperature feedbacks in Antarctica leaves atmospheric radiation balance, along with the possible effects of winter duration, as major determinants of the southern temperature response to orbitally driven changes in insolation. 


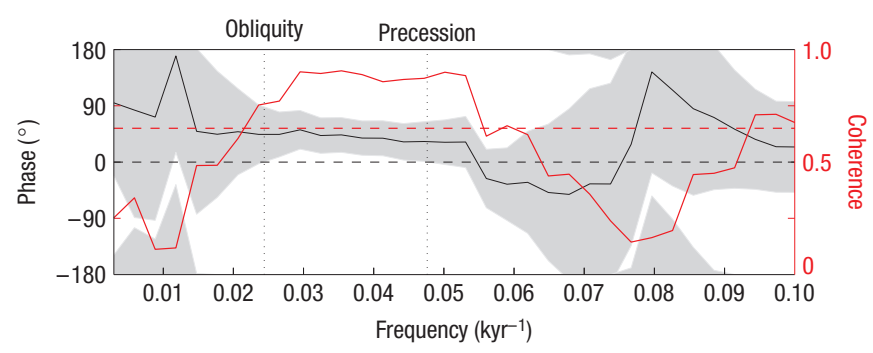

Figure 4 Coherence and phase between proxy and model estimates of mean annual atmospheric temperature at Dome F. A multitaper method is used to estimate the coherence (red line) and phase (black line). A Monte Carlo method is used to estimate the $95 \%$ confidence level for the coherence (red dashed line, indicating that the orbital bands are significantly coherent) and the $95 \%$ confidence interval for the phase (shading, including an age model uncertainty of $\pm 0.75 \mathrm{kyr}$, $1 \sigma)$. Positive phases indicate that the proxies lag behind the model output, and at the orbital bands (vertical dotted lines) results are consistent within uncertainties with an in-phase relationship.

One implication of independent hemispheric responses is that the lead-lag relationships between the hemispheres at orbital timescales need not be indicative of causality. The lead of southern changes relative to northern climate at the orbital bands ${ }^{2}$ can instead be understood from the Antarctic climate remaining in near radiative equilibrium with local insolation whereas northern changes are mediated through the slow response of the northern ice sheets ${ }^{35,36}$. (Note that meltwater pulses enable a rapid northern-ice-sheet response to insolation or other forcing, but that such threshold-like processes are probably more important at timescales shorter than those associated with orbital periods.) The relatively small changes in the glacial-interglacial dimensions of the Antarctic Ice Sheet may also account for the apparently consistent response of Antarctic temperature to orbital variations between interglacial ${ }^{5}$ and glacial times ${ }^{6,7}$.

Finally, we note that the obliquity-and-precession-band variability in Antarctic atmospheric temperature represents only $\sim 20 \%$ of the variance in the $800 \mathrm{kyr} \delta^{18} \mathrm{O}_{\text {ice }}$ Dome $\mathrm{C}$ record, but that the summer-duration hypothesis may also afford insight into the origins of the stronger $\sim 100 \mathrm{kyr}$ variability, which represents $\sim 50 \%$ of the variance. An Antarctic response to local changes in insolation is consistent with hypotheses calling on terminations to be triggered by changes in southern insolation ${ }^{15,39-42}$. If a long summer and a short winter lead to a decrease in production and extent of Antarctic sea ice, they may also increase the outgassing of $\mathrm{CO}_{2}$ from the Southern Ocean by decreasing near-surface stratification ${ }^{34}$. Hence, the coincidence of aphelion with southern summer solstice may coordinate a powerful combination of southern warming agents. Once the northern ice sheets are sufficiently large to become unstable, the combination of a long southern summer and an intense northern summer may be the one-two punch that leads to the collapse of northern ice sheets.

\section{METHODS}

The connection between temperature and insolation is first explored using a simple energy-balance model, $\mathrm{d} T / \mathrm{d} t=\left(F(t)-\sigma T(t)^{4}\right) \epsilon / C$, where $t$ is time. For simplicity, the heat capacity is taken as a constant $\left(C=2,500 \mathrm{~kJ}^{\circ} \mathrm{C}^{-1}\right)$, and the short-wave absorptivity and long-wave emissivity are assumed equal to each other $(\epsilon=0.05)$. When forced by insolation changes at $77^{\circ} \mathrm{S}$, the selected parameters give a seasonal cycle of temperatures ranging between $-60^{\circ}$ and $-10^{\circ} \mathrm{C}$, in agreement with the $700 \mathrm{mb}$ temperatures in the NCEP/NCAR reanalysis ${ }^{43}$ at the Dome Fuji site $\left(77^{\circ} \mathrm{S}\right.$ and $\left.40^{\circ} \mathrm{E}\right)$. Experiments with more complicated versions of the energy-balance model, including constant, periodic, and temperature-dependent parametrization of heat-flux convergence, yield modifications of the seasonal cycle but inevitably give the same effect, namely that a greater summer duration leads to a positive perturbation in annual average temperature.

Temperature is essentially assured to follow simple radiative equilibrium in the energy-balance model, making it useful to also analyse the response of SCAM ${ }^{23,24}$ to orbitally induced changes in insolation. SCAM contains the vertical radiation, cloud and surface-process physics of the NCAR Community Atmospheric Model but spans only a single lateral grid box, here made to coincide with the Dome F ice-core site. We specify a sensible heat-flux convergence of $100 \mathrm{~W} \mathrm{~m}^{-2}$ and a latent heat-flux convergence of $50 \mathrm{~W} \mathrm{~m}^{-2}$, consistent with the annual average convergences over Antarctica found in the NCEP/NCAR reanalysis ${ }^{43}$ (but which are uncertain ${ }^{44}$ ). The latent and sensible heat convergences are distributed so as to generate uniform warming within the troposphere. The simplification of a constant heat convergence avoids building in a particular seasonal cycle ${ }^{45}$ and distinguishes our hypothesis of local insolation control from hypotheses calling on remote variations in climate ${ }^{46}$. Furthermore, the reanalysis indicates that the seasonal cycle in heat flux at Dome $\mathrm{F}$ is only $20 \mathrm{~W} \mathrm{~m}^{-2}$ about a mean consistent with the Antarctic average, suggesting that a constant heat convergence is a reasonable approximation for this site, though the annual cycle in the reanalysis is larger at other sites (for example $140 \mathrm{~W} \mathrm{~m}^{-2}$ at Dome C). The seasonal cycle in temperature produced by SCAM is similar to observations, including reproduction of a thermal inversion layer with an average magnitude of $\sim 15^{\circ} \mathrm{C}$ and a seasonal amplitude of $\sim 50^{\circ} \mathrm{C}$ within the tropospher $e^{25}$.

We integrate SCAM forward using a 20 min time step, and thus resolve the full diurnal and seasonal cycle of insolation as well as the modulation of these quantities by shifts in Earth's orbital configuration ${ }^{47}$ (Fig. 3). The integration is started 350,000 years ago, and the model is run to equilibrium over the course of 25 years. Then, to accelerate the model integrations, the calendar is stepped forward 975 years, and the equilibration process is repeated. Results are averaged over the last 5 years of each of the 350 equilibration runs. SCAM's annual average atmospheric temperature is computed from the pressure-weighted average of the four lowest atmospheric layers (centred at $\sim 580,620,650$ and $660 \mathrm{mb}$ ), but essentially the same variability is present throughout the entire vertical column. Longer runs of the model over the past $800 \mathrm{kyr}$ yield atmospheric and surface variability that, respectively, remain consistent with the duration and insolation intensity of summer as well as with the Dome C atmospheric-temperature proxy record ${ }^{6}$. SCAM also generates results consistent with those reported here when run at the Vostok and Dome C ice-core sites, as well as when run in configurations with a clear sky, no atmospheric heat-flux convergence or lower atmospheric $\mathrm{CO}_{2}$ concentration (180 p.p.m.).

Received 16 June 2008; accepted 26 August 2008; published 21 September 2008.

\section{References}

1. Hays, J. in Antarctic Glacial History and World Palaeoenvironments (ed. Van Zinderen Bakker, E.) 57-71 (A.A. Balkema, Rotterdam, 1978)

2. Imbrie, J. et al. On the structure and origin of major glaciation cycles. 1. Linear responses to Milankovitch forcing. Paleoceanography 7, 701-738 (1992)

3. Lorius, C. et al. A 150, 000-year climatic record from Antarctic ice. Nature 316, 591-596 (1985).

4. Petit, J. et al. Climate and atmospheric history of the past 420,000 years from the Vostok ice core, Antarctica. Nature 399, 429-436 (1999).

5. Masson, V. et al. Holocene climate variability in Antarctica based on 11 ice-core isotopic records. Quat. Res. 54, 348-358 (2000).

6. Jouzel, J. et al. Orbital and millennial Antarctic climate variability over the past 800,000 years. Science 317, 793-796 (2007).

7. Kawamura, K. et al. Northern Hemisphere forcing of climatic cycles in Antarctica over the past 360,000 years. Nature 448, 912-916 (2007).

8. Alley, R., Brook, E. \& Anandakrishnan, S. A northern lead in the orbital band: North-south phasing of Ice-Age events. Quat. Sci. Rev. 21, 431-441 (2002).

9. Barrows, T., Juggins, S., De Deckker, P., Calvo, E. \& Pelejero, C. Long-term sea surface temperature and climate change in the Australian-New Zealand region. Paleoceanography 22, 1-17 (2007).

10. Imbrie, J. et al. On the structure and origin of major glaciation cycles .2. The 100,000-year cycle. Paleoceanography 8, 699-735 (1993).

11. Gildor, H. \& Tziperman, E. Physical mechanisms behind biogeochemical glacial-interglacial $\mathrm{CO}_{2}$ variations. Geophys. Res. Lett. 28, 2421-2424 (2001).

12. Mercer, J. in Climate Processes and Climate Sensitivity Vol. 29 (ed. Ewing, M.) 307-313 (Geophysical Monograph, American Geophysical Union, 1984).

13. Charles, C., Lynch-Stieglitz, J., Ninnemann, U. \& Fairbanks, R. Climate connections between the hemisphere revealed by deep sea sediment core/ice core correlations. Earth Planet. Sci. Lett. 142, 19-27 (1996).

14. Bard, E., Rostek, F. \& Songzogni, C. Interhemispheric synchrony of the last deglaciation inferred from alkenone palaeothermometry. Nature 385, 707-710 (1997).

15. Broecker, W. \& Henderson, G. The sequence of events surrounding Termination II and their implications for the cause of glacial-interglacial $\mathrm{CO}_{2}$ changes. Paleoceanography 13, 352-364 (1998).

16. Huybers, P. \& Curry, W. Links between the annual, Milankovitch, and continuum of climate variability. Nature 441, 329-332 (2006). 
17. Huybers, P Early Pleistocene glacial cycles and the integrated summer insolation forcing. Science 313, 508-511 (2006).

18. Kukla, J. Missing link between Milankovitch and climate. Nature 253, 600-603 (1975).

19. Milankovitch, M. Kanon der Erdbestrahlung und seine Andwendung auf das Eiszeitenproblem (Royal Serbian Academy, Belgrade, 1941).

20. Rubincam, D. Black body temperature, orbital elements, the Milankovitch precession index, and the Seversmith psychroterms. Theor. Appl. Climatol. 79, 111-131 (2004).

21. Kim, S., Crowley, T. \& Stossel, A. Local orbital forcing of Antarctic climate change during the last interglacial. Science 280, 728-730 (1998).

22. Stott, L., Timmermann, A \& Thunell, R. Southern Hemisphere and deep-sea warming led deglacial atmospheric $\mathrm{CO}_{2}$ rise and tropical warming. Science 318, 435-438 (2007).

23. Hack, J., Truesdale, J., Pedretti, J. \& Petch, J. SCAM user's guide. $<$ http://www.ccsm.ucar.edu/models/atm-cam/docs/scam/> (2004).

24. Collins, W. et al. The formulation and atmospheric simulation of the community atmosphere model version 3 (CAM3). J. Clim. 19, 2144-2161 (2006).

25. Hudson, S. \& Brandt, R. A look at the surface-based temperature inversion on the Antarctic Plateau. J. Clim. 18, 1673-1696 (2005).

26. Vimeux, F., Cuffey, K. \& Jouzel, J. New insights into Southern Hemisphere temperature changes from Vostok ice cores using deuterium excess correction. Earth Planet. Sci. Lett. 203, 829-843 (2002).

27. Van Lipzig, N., Van Meijgaard, E. \& Oerlemans, J. The effect of temporal variations in the surface mass balance and temperature-inversion strength on the interpretation of ice-core signals. J. Glaciol. 48, 611-621 (2002)

28. Bender, M. Orbital tuning chronology for the Vostok climate record supported by trapped gas composition. Earth Planet. Sci. Lett. 204, 275-289 (2002).

29. Gildor, H. \& Ghil, M. Phase relations between climate proxy records: Potential effect of seasonal precipitation changes. Geophys. Res. Lett. 29, 1-4 (2002).

30. Wolff, E. W. et al. Southern Ocean sea-ice extent, productivity and iron flux over the past eight glacial cycles. Nature 440, 491-496 (2006).

31. Siegenthaler, U. et al. Stable carbon cycle-climate relationship during the late Pleistocene. Science 310, 1313-1317 (2005).

32. Lüthi, D. et al. High-resolution carbon dioxide concentration record $650,000-800,000$ years before present. Nature 453, 379-382 (2008).

33. Stephens, B. \& Keeling, R. The influence of Antarctic sea ice on glacial-interglacial $\mathrm{CO}_{2}$ variations. Nature 404, 171-174 (2000).

34. Sigman, D. \& Boyle, E. Palaeoceanography: Antarctic stratification and glacial $\mathrm{CO}_{2}$. Nature 412 605-606 (2001).

35. Imbrie, J. \& Imbrie, J. Modeling the climatic response to orbital variations. Science 207, 943-953 (1980).

36. Roe, G. In defense of Milankovitch. Geophys. Res. Lett. 33, 1-4 (2006).
37. Adhémar, J. A. Révolutions de la Mer: Déluges Períodiques (Carilian-Goeury et V. Dalmont, Paris, 1842).

38. Denton, G. \& Hughes, T. Reconstructing the Antarctic Ice Sheet at the Last Glacial Maximum. Quat. Sci. Rev. 21, 193-202 (2002).

39. Henderson, G. \& Slowey, N. Evidence from U-Th dating against Northern Hemisphere forcing of the penultimate deglaciation. Nature 404, 61-66 (2000).

40. Parrenin, F., Jouzel, J., Waelbroeck, C., Ritz, C. \& Barnola, J. Dating the Vostok ice core by an inverse method. J. Geophys. Res. 106(D23), 31837-31851 (2001).

41. Shackleton, N. J. The 100,000-year ice-age cycle identified and found to lag temperature, carbon dioxide, and orbital eccentricity. Science 289, 1897-1902 (2000).

42. Schulz, K. \& Zeebe, R. Pleistocene glacial terminations triggered by synchronous changes in Southern and Northern Hemisphere insolation: The insolation canon hypothesis. Earth Planet. Sci. Lett. 249, 326-336 (2006).

43. Kalnay, E. et al. The NCEP/NCAR 40-year reanalysis project. Bull. Am. Meteorol. Soc. 77, 437-471 (1996).

44. Hines, K., Grumbine, R. W., Bromwich, D. \& Cullather, R. Surface energy balance of the NCEP MRF and NCEPNCAR reanalysis in Antarctic latitudes during FROST. Weath. Forecast. 14, 851-866 (1999).

45. Joussaume, S. \& Braconnot, P. Sensitivity of paleoclimate simulation results to season definitions. J. Geophys. Res. 102, 1943-1956 (1997).

46. Vimeux, F., Masson, V., Jouzel, J., Stievenard, M. \& Petit, J. Glacial-interglacial changes in ocean surface conditions in the Southern Hemisphere. Nature 398, 410-413 (1999).

47. Berger, A. \& Loutre, M. F. Astronomical solutions for paleoclimate studies over the last 3 million years. Earth Planet. Sci. Lett. 111, 369-382 (1992).

Supplementary Information accompanies the paper at www.nature.com/naturegeoscience.

\section{Acknowledgements}

This manuscript benefited from comments by R. Alley, D. Barrell, P. Blossey, I. Eisenman, J. Gebbie, A. Giese, K. Kawamura, R. Pierrehumbert, A. Stine and J. Severinghaus. We are also grateful to $\mathrm{K}$. Kawamura for providing the $\delta \mathrm{O}_{2} / \mathrm{N}_{2}$ record and to C. Walker and D. Abbot for technical assistance. P.H. received support from the Comer Science and Education Foundation (CSEF) and NSF award 0645936. G.D. is supported by NOAA and CSEF.

\section{Author information}

Reprints and permission information is available online at http://npg.nature.com/reprintsandpermissions. Correspondence and requests for materials should be addressed to P.H. 